
\title{
25 Research Square \\ In-Vitro Investigation of Antimicrobial Effect of Bark Root Extracts of Solanum Incanum and Croton Macrostachyus
}

Moa Melaku Shigut ( $\square$ moalove.3@gmail.com )

Jimma University College of Agriculture and Veterinary Medicine https://orcid.org/0000-0002-40976644

\section{Tagesu Abdisa Serbessa}

Jimma University College of Agriculture and Veterinary Medicine

Dele Abdissa Keneni

Jimma University College of Natural Sciences

Feyissa Begna Deressa

Jimma University College of Agriculture and Veterinary Medicine

Motuma Debelo

Jimma University College of Agriculture and Veterinary Medicine

Research article

Keywords: Antibacterial, C. macrostachyus extract, E. coli, S. incanum extract, Solvents, S. 43 aureus

Posted Date: October 12th, 2020

DOl: https://doi.org/10.21203/rs.3.rs-88900/v1

License: (c) (1) This work is licensed under a Creative Commons Attribution 4.0 International License.

Read Full License 


\section{Abstract}

Background: The increasing antibiotic resistance exhibited by pathogenic microbial infectious agents has led to the screening of several medicinal plants for their potential antimicrobial activity. An in vitro experimental investigation was conducted with the aim to evaluate antibacterial effect of bark root extracts of S. incanum and C. macrostachyus against $\mathrm{S}$. aureus and $\mathrm{E}$. coli. It was experimental study from January 2019 to November 2019 in Jimma University. The crude extracts of S. incanum and C. macrostachyus were done using petroleum ether, ethanol and distilled water by maceration methods. The antibacterial activity tests were assessed using agar well diffusion and minimum inhibition concentration methods.

Results: C. macrostachyus bark rout ethanol extracts have shown an antibacterial effect against E. coli and $S$. aureus with maximum mean zone of inhibition of $15 \pm 0.58 \mathrm{~mm}$ and $17.33 \pm 0.89 \mathrm{~mm}$ respectively. In case of $\mathrm{S}$. incanum it is also the ethanol extract that showed highest mean zone of inhibition of $22.67 \pm 0.89 \mathrm{~mm}$ and $22.33 \pm 0.89 \mathrm{~mm}$ against $E$. coli and $S$. aureus respectively. The positive control Gentamicin $(10 \mu \mathrm{gm} / \mathrm{disc})$ inhibited the growth of E. coli and S. aureus with recorded mean zone of inhibition about $23 \pm 0.58 \mathrm{~mm}$ and $24.67 \pm 0.33 \mathrm{~mm}$ respectively. Therefore the ethanol extract of Croton macrostachyus and $\mathrm{S}$. incanum showed minimum inhibitor concentration against $\mathrm{S}$. aureus and E. coli than other solvents.

Conclusion: Bioactive compounds of medicinal plant extracts have been used to overcome the challenges of antimicrobial resistance. The current experimental study showed that, the bark root extract of Solanum incanum and Croton macrostachyus have high potent of antibacterial activities against $\mathrm{E}$. coli and S. aureus. This study therefore substantiates the use of Solanum incanum and Croton macrostachyus as an antimicrobial medicinal plant.

\section{Full Text}

This preprint is available for download as a PDF.

\section{Figures}



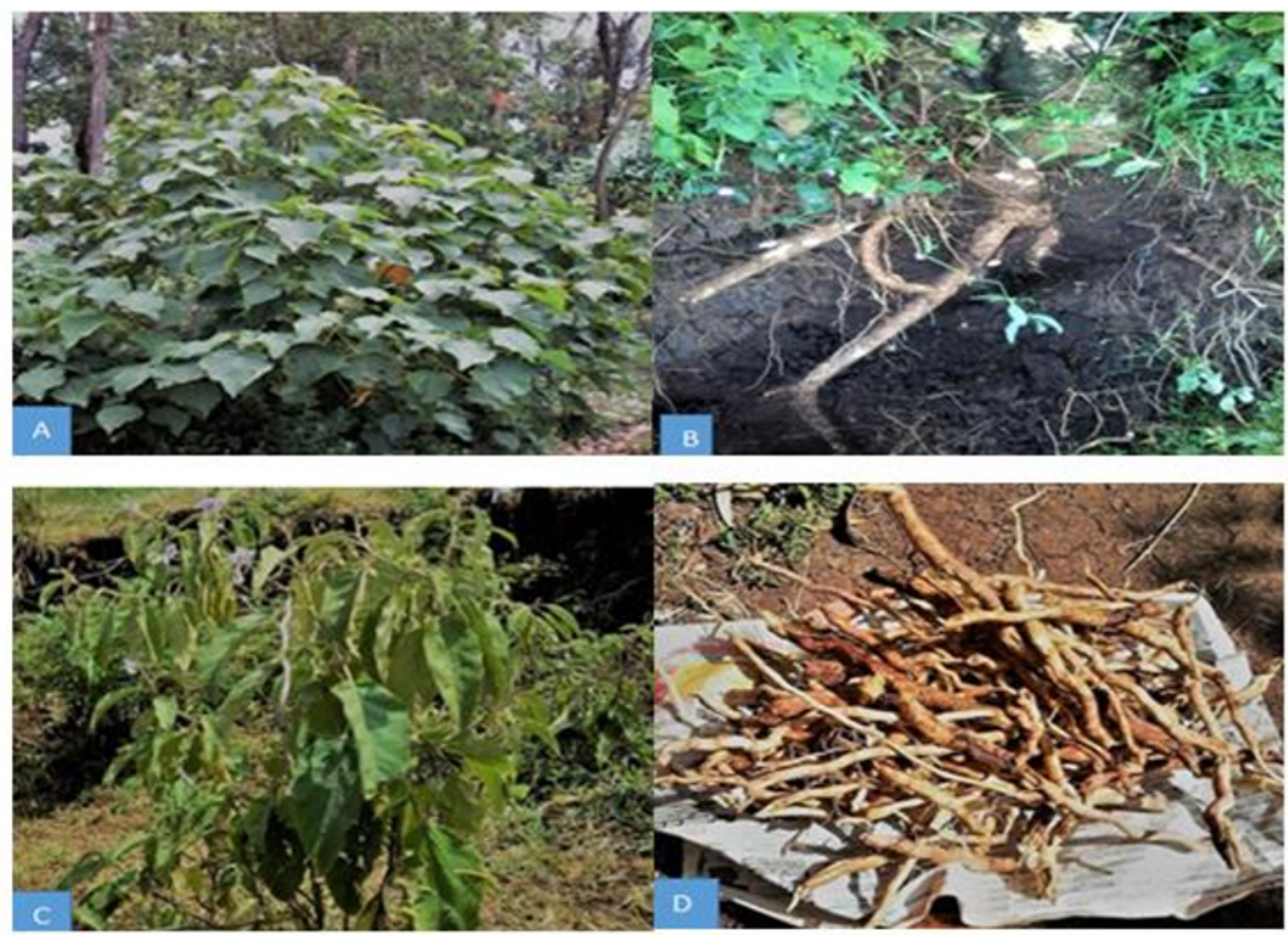

\section{Figure 1}

medicinal plants used during the study period; $A$ and $B$ : Croton macrostachyus with its root; C and D: Solanum incanum and its root 